\title{
Inhibition of Fusarium solani in transgenic insect-resistant cotton plants treated with silver nanoparticles from Prosopis glandulosa and Pluchea sericea
}

\author{
Ali Abdelmoteleb, Daniel Gonzalez-Mendoza*, Benjamin Valdez-Salas, Onecimo Grimaldo-Juarez \\ and Carlos Ceceña-Duran
}

\begin{abstract}
The phytosynthesis of nanoparticles is a green chemistry approach that combines nanotechnology and bioactive compounds of plants. The aim of this study was to evaluate the effect of silver nanoparticles (AgNPs) from Prosopis glandulosa and Pluchea sericea, respectively, on the control of Fusarium solani previously inoculated in the rhizosphere of transgenic insect-resistant cotton plants. The results showed that the weekly application of AgNPs from $P$. glandulosa and $P$. sericea caused a diminution of fungal propagules in the soil after 30 days of treatment. In this sense, the AgNPs from $P$. glandulosa were more efficient in the reduction of infection points in the roots of the plants infected with F. solani compared with AgNPs from P. sericea. Additionally, the application of AgNPs from both plants showed a significant increase of optimum quantum yield (Fv/Fm), stomata conductance $\left(g_{s}\right)$, and the number of lateral roots in transgenic insect-resistant cotton plants after 30 days of exposure when compared to the control. Based on our results, AgNPs from P. glandulosa and P. sericea could inhibit growth of Fusarium solani. However, more extensive and elaborate studies are needed to explain the different mechanisms that participate in the inhibition of growth of fungus using nanoparticles from these plants.
\end{abstract}

Keywords: Biocontrol, Native plants, Phytonanoparticles, Antifungal activity, Green synthesis

\section{Background}

Cotton (Gossypium hirsutum L.) is the most economically important crop in the global textile industry and constitutes more than half of all textile fiber consumption worldwide (Karademir et al. 2011). A great achievement in cotton breeding was the development of transgenic pureline varieties or hybrids containing the crystal (cry) genes of Bacillus thuringiensis (Bt) encoding insecticidal proteins $(\delta$-endotoxin) that provide protection from lepidopteran pests (Terán-Vargas et al. 2005). The adoption of $B t$ transgenic cotton varieties in countries as Argentina, Brazil, Colombia, and Mexico helped to reduce the cost of insecticide applications and increased yield of this crop (TeránVargas et al. 2005). For example, Mexico has adopted this new technology, and 9 years after commercial release, $B t$

\footnotetext{
* Correspondence: daniasaf@gmail.com

Universidad Autónoma de Baja California, Mexicali, Baja California, Mexico
}

transgenic cotton reached 133,000 ha planted in Mexico in 2015/16 according to the Agrifood and Fisheries Information Service (SIAP) of the Secretariat of Agriculture, Livestock, Rural Development, Fishing and Food (https:// www.gob.mx/siap/). However, the presence of fungal phytopathogens during the development of plants is very important because these organisms can lead to wilt or root rot disease that causes substantial losses to farmers (AbdElsalam 2003). Fusarium wilt is an important disease present in cotton plants in diverse countries, which is caused by Fusarium solani (González Soto et al. 2015). These pathogens cause root rot, damping-off symptoms, and reduction in the size of leaves and bolls, which affect the yield and fiber quality (González Soto et al. 2015).

Diverse studies reported the use of different control measures for Fusarium species associated with plants. These measures include the application of agronomic control techniques, genetic resistance, and use of 
chemical or biological antagonists (Aquino-Martinez et al. 2008; Baffoni et al. 2015). Currently, environmental hazards caused by the use of fungicides and the unpredictable results of biological control have been widely debated (Adesina et al. 2007). Therefore, researchers are searching for alternative measures that together with biological control and optimal use of fungicides provide major control of fungal diseases in plants (Baffoni et al. 2015). In this sense, the use of the antimicrobial activity of nanoparticles could be presented as a potential alternative for reducing the use of chemicals in agriculture. For example, silver nanoparticles (AgNPs) display diverse modes of inhibitory action against various pathogens such as fungi and bacterial species (Yamanaka et al. 2005; Lamsal et al. 2011). In this sense, the AgNPs may be used with relative safety for control of fungal diseases in plants compared to synthetic fungicides, as the applications of AgNPs against Fusarium species associated with transgenic insect-resistant cotton has not been reported. Thus, the main objective of the present study was to evaluate the inhibition of fungal growth of $F$. solani in transgenic insect-resistant cotton treated with silver phytonanoparticles from Prosopis juliflora and Pluchea sericea.

\section{Materials and methods}

\section{Germination of transgenic insect-resistant cotton}

Bollgard $^{\circ}$ cotton transgenic seeds were provided by producers of the cotton product system of Baja California, Mexico. The seeds were superficially disinfected by immersion in a $0.5 \%$ sodium hypochlorite solution for $3 \mathrm{~min}$ followed by washes with sterile deionized water. After disinfection, the seeds were placed in single pots $(0.3 \mathrm{~L})$ containing a commercial potting soil mix combined with quartz sand and peat moss sterilized by autoclaving at $121{ }^{\circ} \mathrm{C}$ for $2 \mathrm{~h}$. The seeds were subjected to 12-h light/dark photoperiods with $60 \%$ relative air humidity (Gonzalez-Mendoza et al. 2013).

\section{Synthesis of silver nanoparticles}

The silver nanoparticles from the leaf extract of Prosopis glandulosa and $P$. sericea used in the present study were previously obtained by Abdelmoteleb et al. (2016, 2017). The bioreduction of $\mathrm{Ag}^{+}$ions was observed by color change from yellow to brown, indicating the formation of AgNPs at room temperature. The silver nanoparticles that formed in the reaction solution showed a particle size average from 421 ( $P$. glandulosa) to $59.20 \mathrm{~nm}$ (P. sericea) according to Abdelmoteleb et al. (2016, 2017). The AgNPs of P. glandulosa and P. sericea used in this experiment were previously diluted with deionized water at $100 \mathrm{ppm}$.

\section{Fusarium solani inoculant formulation}

Fusarium solani T-ICA04 was previously isolated from two different sites of transgenic insect-resistant cotton growing in fields of Baja California $\left(32^{\circ} 24^{\prime} 12.26^{\prime \prime} \mathrm{N}\right.$, $115^{\circ} 9^{\prime} 13.60^{\prime \prime} \mathrm{W}$ and $32^{\circ} 28^{\prime} 5.63^{\prime \prime} \mathrm{N}, 115^{\circ} 12^{\prime} 11.94^{\prime \prime}$ W). This strain was characterized molecularly and deposited in GenBank with the accession number KJ620372. The formulation of inoculant was produced in potato-dextrose (PDB) broth for 5 days at $28 \pm 2{ }^{\circ} \mathrm{C}$. The conidial suspension was then quantified by the aid of an automated cell counter $\left(\mathrm{TC} 20^{\mathrm{mm}}\right.$, Bio-Rad) and diluted with water. Suspensions obtained were mixed uniformly with soil mix combined with quartz sand and peat moss. The soil was allowed to dry for about 3 weeks at room temperature (about $25-28{ }^{\circ} \mathrm{C}$ ). The amount of Fusarium propagules was evaluated by the dilution plate method on PDA agar (González Soto et al. 2015).

\section{Inoculation with Fusarium solani and exposure to silver nanoparticles}

Once the seedlings developed a few roots, they were transplanted into single pots $(0.2 \mathrm{~L})$ containing a commercial potting soil mix combined with quartz sand, and infested soil with $F$. solani (prepared as described above) was added in the proportion of 3:1 v/v to the uninfested soil to obtain a final concentration of $1 \times 10^{5}$ count $\mathrm{g}^{-1}$ soil of Fusarium solani propagules. After the inoculation, the seedlings were divided into three groups: (1) inoculated (control), (2) inoculated + AgNPs from $P$. glandulosa, and (3) inoculated + AgNPs from P. sericea. Groups 2 and 3 with $F$. solani inoculant were weekly irrigated with AgNPs (100 ppm) from P. glandulosa and $P$. sericea, respectively. The control plants (group 1) were irrigated only with deionized water. The amount of Fusarium propagules in each treatment was evaluated 30 days after application of AgNPs (González Soto et al. 2015). All groups were replicated 10 times and grown in a growth chamber with 12-h light/dark photoperiods with $60-70 \%$ relative humidity.

\section{Evaluation of physiological parameters}

The stomata conductance $\left(g_{\mathrm{s}}\right)$ of young fully expanded leaves was measured at 30 days after exposure to treatments with AgNPs from P. glandulosa and P. sericea, respectively, using a portable leaf porometer (SC-1, Decagon, USA) according to Gonzalez-Mendoza et al. (2013). On the other hand, the chlorophyll fluorescence was measured using a portable chlorophyll fluorometer (OS30p, OptiSciences). It represented optimum quantum yield ( $\mathrm{Fv} / \mathrm{Fm})$ evaluated at $27{ }^{\circ} \mathrm{C}$, and time range was $10 \mu$ s to $3 \mathrm{~s}$. For each studied parameter $\left(g_{\mathrm{s}}\right.$ and $\left.\mathrm{Fv} / \mathrm{Fm}\right), 10$ individual leave$\mathrm{s}$-young, completely developed, and healthy-were measured within each treatment. 


\section{Evaluation of morphological parameters}

After 30 days of inoculation with $F$. solani, lateral roots (LR) of each seedling treatment were evaluated. The lateral root was classified according to the number of roots of second orders using a stereomicroscope. This variable is an essential and continuous process in the formation of root systems and is important for evaluation in the present study.

\section{Number of lesions produced by the pathogen}

The brown lesions characteristic of $F$. solani infection, observed on the system Radical (Espinosa-Victoria et al. 2004), were quantified 30 days after inoculation with the pathogen, with the aid of a stereoscopic microscope, in 10 seedlings of each treatment.

\section{Statistical analysis}

The experiment was set up in a completely randomized design with 10 replications. The significant differences between the AgNP-treated and control samples were analyzed using the Kruskal-Wallis test (Statistical Package version 5.5, StatSoft, USA).

\section{Results and discussion}

Data showed that addition of AgNPs from P. glandulosa and $P$. sericea had different effects on the amount of Fusarium propagules in the soil of the different treatments (Fig. 1a). For example, the highest decrease of fungal propagules was observed after the addition of AgNPs from $P$. glandulosa to infested soil (Fig. 1b). In this sense, also the addition of AgNPs from P. sericea stimulated decrease of the Fusarium population but in minor proportion. In contrast, the highest number of Fusarium colonies was obtained from the control samples where AgNPs from the plants were not added (Fig. 1b). On the other hand, the transgenic insect-resistant cotton plants inoculated with $F$. solani, and treated with AgNPs from P. glandulosa and $P$. sericea, respectively, exhibited significant changes in the optimum quantum yield $(\mathrm{Fv} / \mathrm{Fm})$ values with respect to the control (Fig. 2b). The effect of AgNPs from both plants showed a significant increase of stomata conductance $\left(g_{\mathrm{s}}\right)$ after 30 days of exposure (Fig. 2a). In contrast, the transgenic insect-resistant cotton plants inoculated only with $F$. solani exhibited significant reduction in $\mathrm{Fv} / \mathrm{Fm}$ and $g_{\mathrm{s}}$ values compared with the plants treated with AgNPs (Fig 2). In the present study, both AgNPs from P. glandulosa and $P$. sericea caused decreased infection points in roots when compared with control plants $(P \leq 0.05)$ after 30 days of exposure (Fig. 3). AgNPs from P. glandulosa were more efficient in the reduction of infection points in the plants infected with $F$. solani compared with AgNPs from $P$. sericea. On the other hand, the effect of AgNPs from both plants showed a significant increase of number of lateral roots in transgenic insect-resistant cotton plants

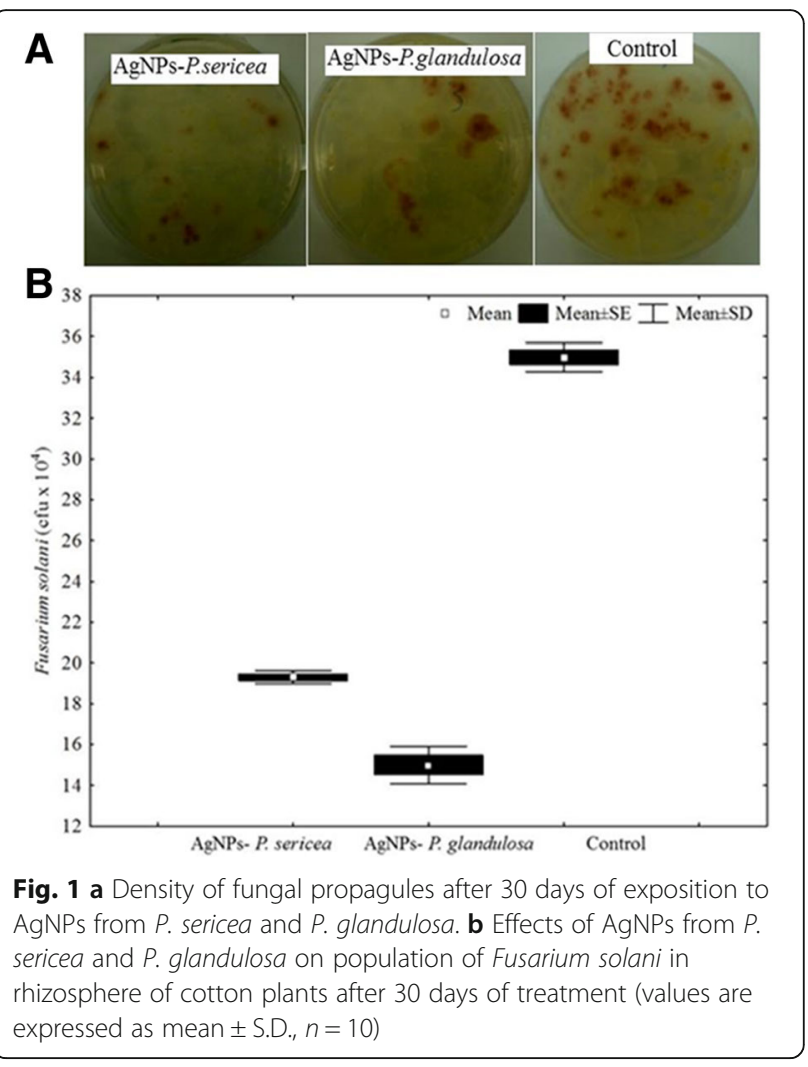

after 30 days of exposure when compared to the control $(P \leq 0.05)$ (Fig. 4a, b).

Previous studies indicated that the antifungal activity in vitro of AgNPs influences colony formation of spores and disease progression of different plant pathogenic fungi (Kim et al. 2012). The results clearly demonstrated that the silver nanoparticles obtained from these native plants have the potential to inhibit F. solani. However, the mechanism behind this activity is not yet fully explored. In this sense, there are various theories suggesting about the action of AgNPs on fungal phytopathogens. For example, certain authors reported that AgNPs produce free radicals which can cause damage to the protein and lipid membrane followed by destruction of microorganisms (Jung et al. 2010; Aguilar-Méndez et al. 2011; Kim et al. 2012). In this respect, further studies are required to confirm the potential of AgNPs from P. glandulosa and $P$. sericea for the control of Fusarium solani principally under field conditions. On the other hand, silver nanoparticles are known to produce positive and negative effects on growth and physiological parameters in plants (Stampoulis et al. 2009; Zuverza-Mena et al. 2016; Jasim et al. 2017). Similarly, Raliya et al. (2015) found that the application of nanoparticles from different metals on tomato seedlings after 1 week caused an abnormal proliferation of root hairs compared to the control group. The effect on lateral roots observed in the present study could 

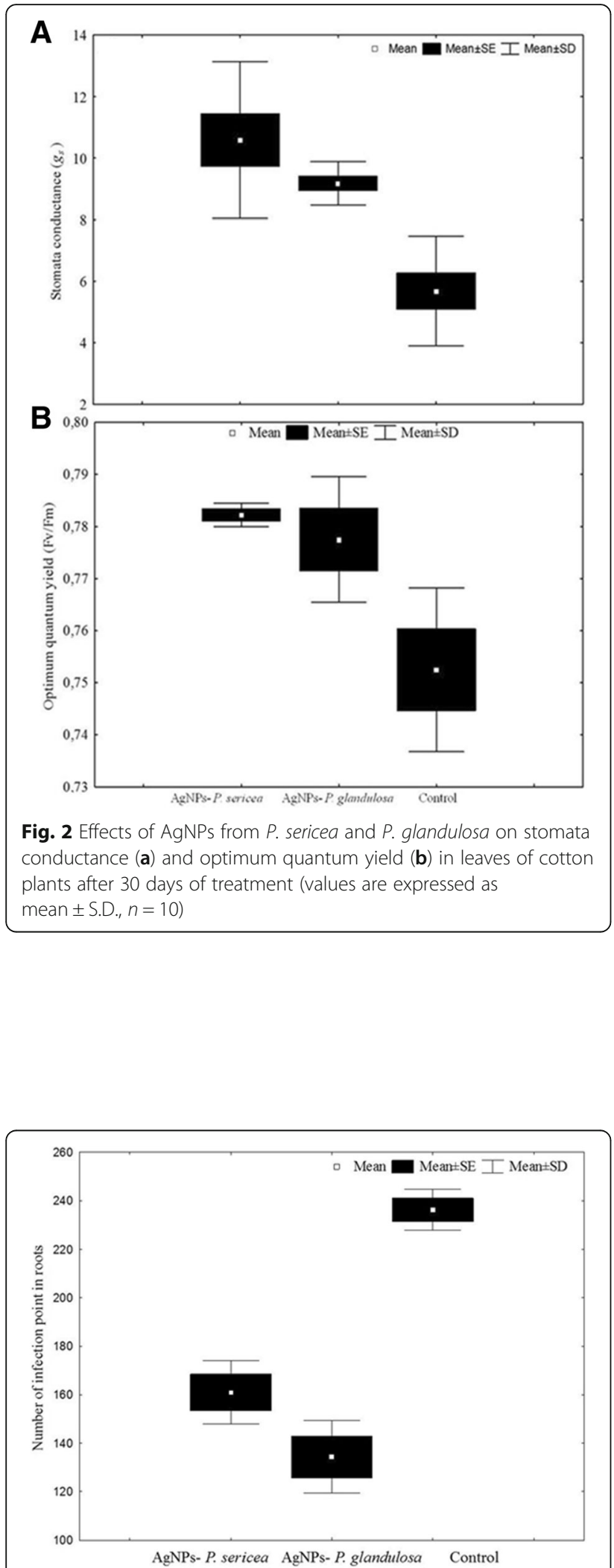

Fig. 3 Modification in the number of infection points in roots of cotton plants after 30 days of treatment with AgNPs from P. sericea and $P$. glandulosa (values are expressed as mean \pm S.D., $n=10$ )

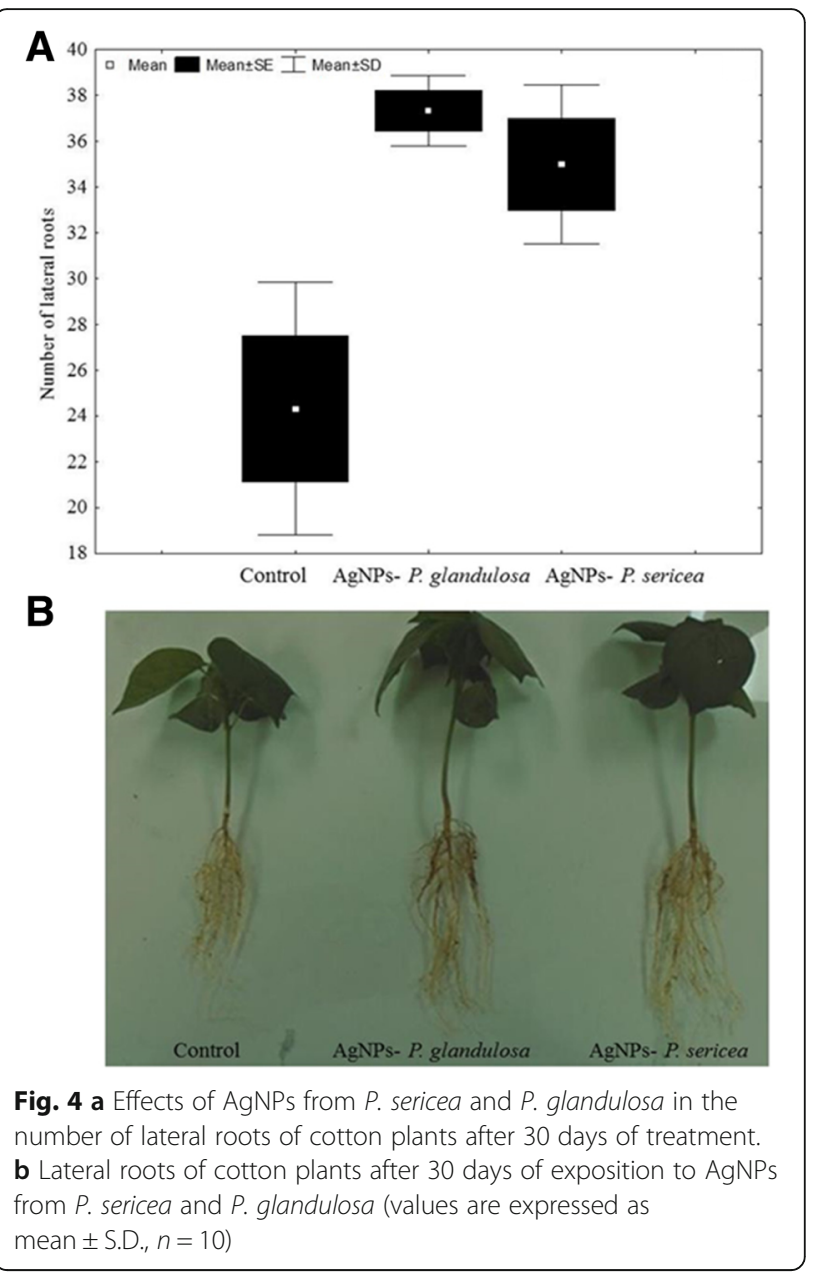

be explained by the hormesis effect, which is an adaptive response at the concentrations of nanoparticles used and by inhibition of development of pathogenic fungus in the roots by the nanoparticles employed (Nascarella and Calabrese 2012; Xia et al. 2016). On the other hand, previous studies have shown that infection of plants by Fusarium sp. results in a diminution of optimum quantum yield (Fv/ Fm) and stomata conductance $\left(g_{\mathrm{s}}\right)$ due to reduced water and nutrient uptake by roots (Ye et al. 2004). In this sense, our study showed that the optimum quantum yield $(\mathrm{Fv} / \mathrm{Fm})$ and stomata conductance $\left(g_{\mathrm{s}}\right)$ was significantly increased in cotton plants treated with $\mathrm{Ag}$ nanoparticles from $P$. glandulosa and P. sericea, suggesting that the use of nanoparticles prevented the $F$. solani invasion in the roots favoring water transport in the cotton plants. On the other hand, the increased optimum quantum yield (Fv/ Fm) and stomata conductance $\left(g_{\mathrm{s}}\right)$ in cotton plants with respect to the control were in contrast with the report of Da Costa and Sharma (2016) who reported a decrease of Fv/ Fm and $g_{\mathrm{s}}$ as a result of nanoparticle exposure in Oryza sativa. However, Li et al. (2013) observed that the use of nanoparticles on watermelon increased seedling germination 
and enhanced physiological parameters. Considering the earlier works, the effect of nanoparticles can vary for different morphological and physiological attributes on plants.

\section{Conclusions}

In conclusion, the uses of $\mathrm{Ag}$ nanoparticles from P. sericea and $P$. glandulosa could inhibit growth of $F$. solani and showed considerable antifungal activity in cotton plants infected with $F$. solani. Therefore, the application of nanoparticles as nanofungicides is relatively a new approach in agricultural sectors. Therefore, more elaborate studies are needed to explain different mechanisms of growth inhibition of fungus using nanoparticles from the plants and to evaluate economic feasibility of application in field.

\section{Acknowledgements}

This study was supported by the Secretaria de Fomento Agropecuario (SEFOA) Baja California, Mexico, and Conacyt Ciencia Basica 2013 (\# 219750).

\section{Authors' contributions}

AA carried out the experiment. DGM participated in design of study. BVS participated in coordination of study. OGJ participated in statistical analysis. CCD participated in statistical analysis. All authors read and approved the final manuscript.

\section{Competing interests}

The authors declare that they have no competing interests.

\section{Publisher's Note}

Springer Nature remains neutral with regard to jurisdictional claims in published maps and institutional affiliations.

Received: 10 July 2017 Accepted: 6 December 2017

Published online: 30 January 2018

\section{References}

Abdelmoteleb A, Valdez-Salas B, Carrillo-Beltran M, Duran-Hernandez D, Gonzalez-Mendoza D (2016) Green synthesis of silver nanoparticles using Pluchea sericea a native plants from Baja California, Mexico and their potential application as antimicrobials. Iran J Sci Technol Trans A Sci. in press. https://doi.org/10.1007/s40995-016-0019-6), https://doi.org/10.1007/ s40995-016-0019-6)

Abdelmoteleb A, Valdez-Salas B, Ceceña-Duran C, Tzintzun-Camacho O, GutiérrezMiceli F, Grimaldo-Juarez O, González-Mendoza D (2017) Silver nanoparticles from Prosopis glandulosa and their potential application as biocontrol of Acinetobacter calcoaceticus and Bacillus cereus. Chem Spec Bioavailab 29:1-5

Abd-Elsalam KA (2003) Non-gel based techniques for plant pathogen genotyping. Acta Microbiol Pol 52:329-341

Adesina MF, Lembke A, Costa R, Speksnijder A, Smalla K (2007) Screening of bacterial isolates from various European soils for in vitro antagonistic activity towards Rhizoctonia solani and Fusarium oxysporum: site-dependent composition and diversity revealed. Soil Biol Biochem 39:2818-2828

Aguilar-Méndez MA, Martín-Martinez ES, Ortega-Arroyo L, Cobián-Portillo G, Sánchez-Espíndola E (2011) Synthesis and characterization of silver nanoparticles: effect on phytopathogen Colletotrichum gloesporioides. J Nanopart Res 13:2525-2532

Aquino-Martinez JG, Vazquez-Garcia LM, Reyes-Reyes BG (2008) Biocontrol in vitro e in vivo de Fusarium oxysporum Schlecht.f. sp. Dianthi (Prill. Y Delacr.) snyder y Hans con hongos antagonistas nativos de la zona florícola de villa Guerrero. Rev Mex Fitopatol 26:127-113

Baffoni L, Gaggia F, Dalanaj N, Prodi A, Nipoti P, Pisi A, Biavati B, Di Gioia D (2015) Microbial inoculants for the biocontrol of Fusarium spp. in durum wheat. BMC Microbiol 15:242

Da Costa MVJ, Sharma PK (2016) Effect of copper oxide nanoparticles on growth, morphology, photosynthesis, and antioxidant response in Oryza sativa. Photosynthetica 54:110-119
Espinosa-Victoria D, González-Mendoza D, Placencia-de la Parra J, García-Espinosa R (2004) Reducción de la incidencia de Phytophthora capsici Leo en el sistema radical de plántulas de chile pre-micorrizadas con Glumus intraradices. TERRA Latinoamericana 22:317-326

González Soto T, González-Mendoza D, Troncoso-Rojas R, Morales-Trejo A, Ceceña-Duran C, Grimaldo-Juárez O (2015) Molecular identification of Fusarium species isolated from transgenic insect-resistant cotton plants in Mexicali valley, Baja California. Genet Mol Res 14:11739-11744

Gonzalez-Mendoza D, Escoboza-Garcia F, Santamaria JM, Zapata-Perez O (2013) Copper stress on photosynthesis of black mangle (Avicennia germinans). An Acad Bras Cienc 85:665-670

Jasim B, Thomas R, Mathew J, Radhakrishnan EK (2017) Plant growth and diosgenin enhancement effect of silver nanoparticles in fenugreek (Trigonella foenum-graecum L.) Saudi. Pharm J 25:443-447

Jung JH, Kim SW, Min JS, Kim YJ, Lamsal K, Kim KS, Lee YS (2010) The effect of nano-silver liquid against the white rot of the green onion caused by Sclerotium cepivorum. Mycobiology 38:39-45

Karademir C, Karademir E, Gencer O (2011) Yield and fiber quality of F 1 and F 2 generations of cotton (Gossypium hirsutum L.) under drought stress conditions. Bulg J Agric Sci 17:795-805

Kim SW, Jung JH, Lamsal K, Kim YS, Min YS, Lee S (2012) Antifungal effects of silver nanoparticles (AgNPs) against various plant pathogenic fungi. Mycobiology 40:53-58

Lamsal K, Kim SW, Jung JH, Kim YS, Kim KS, Lee YS (2011) Application of silver nanoparticles for the control of Colletotrichum species in vitro and pepper anthracnose disease in field. Mycobiology 39:194-199

Li J, Chang PR, Huang J, Wang Y, Yuan H (2013) Physiological effects of magnetic iron oxide nanoparticles towards watermelon. J Nanosci Nanotechnol 13:5561-5567

Nascarella MA, Calabrese EJ (2012) A method to evaluate hormesis in nanoparticle dose-responses. Dose Response 10:344-354

Raliya R, Nair R, Chavalmane S, Wang WN, Biswas P (2015) Mechanistic evaluation of translocation and physiological impact of titanium dioxide and zinc oxide nanoparticles on the tomato (Solanum lycopersicum L) plant. Metallomics 7:1584-1594

Stampoulis D, Sinha SK, White JC (2009) Assay-dependent phytotoxicity of nanoparticles to plants. Environ Sci Technol 43:9473-9479

Terán-Vargas AP, Rodríguez JC, Blanco CA, Martínez-Carrillo JL, Cibrián-Tovar J, Sánchez-Arroyo H, Rodríquez-Del-Bosque LA, Stanley D (2005) Bollgard cotton and resistance of tobacco budworm (Lepidoptera: Noctuidae) to conventional insecticides in the southern Tamaulipas. Mexico J Econ Entomol 98:2203-2209

Xia ZK, Ma QH, Li SY, Zhang DQ, Cong L, Tian YL, Yang RY (2016) The antifungal effect of silver nanoparticles on Trichosporon asahii. J Microbiol Immunol Infect 49:182-188

Yamanaka M, Hara K, Kudo J (2005) Bactericidal actions of a silver ion solution on Escherichia coli, studied by energy-filtering transmission electron microscopy and proteomic analysis. Appl Environ Microbiol 71:7589-7593

Ye SF, Yu JQ, Peng YH, Zheng JH, Zou LY (2004) Incidence of Fusarium wilt in Cucumis sativus $L$. is promoted by cinnamic acid, an autotoxin in root exudates. Plant Soil 263:143-150

Zuverza-Mena N, Armendariz R, Peralta-Videa JR, Gardea-Torresdey JL (2016) Effects of silver nanoparticles on radish sprouts: root growth reduction and modifications in the nutritional value. Front Plant Sci 7:90 